See Article page 1426.

\section{Commentary: Innominate artery cannulation for antegrade cerebral perfusion: Keeping the light bulb lit}

\author{
Adam R. Williams, MD, and Edward P. Chen, MD
}

Peterson and colleagues ${ }^{1}$ report the results of a randomized trial comparing axillary versus innominate artery cannulation for antegrade cerebral perfusion (ACP) during hypothermic circulatory arrest (HCA) in 111 patients undergoing proximal aortic arch surgery. The primary safety outcome was the presence of new severe ischemic lesions on diffusion-weighted magnetic resonance imaging (DW-MRI) and was no different in patients cannulated via the axillary artery $(38.8 \%)$ or innominate artery $(34 \%)$. Secondary safety outcomes of stroke/transient ischemic attack were also similar between groups $(7.1 \%$ axillary and $3.6 \%$ innominate; $P=.43$ ), as were neurocognitive assessments. The authors conclude that the innominate artery is a reliable and safe alternative to the axillary artery in cannulation for ACP during elective aortic surgery.

Adequate neurologic protection is paramount for successful outcomes in aortic arch surgery. Cerebral protection strategies have undergone significant evolution over the past 50 years, but remain rooted in the use of HCA and either ACP or retrograde cerebral perfusion (RCP). Traditional outcomes measured include operative mortality and clinical evidence of either permanent stroke or temporary neurologic dysfunction.

The optimal method of cerebral protection has yet to be determined. Numerous comparative studies have been published, the majority of which have demonstrated equivalent outcomes no matter what degree of HCA is utilized or what method of cerebral perfusion is employed. These studies are limited by lack of randomization and being retrospective, single-institution reviews without a control group or sufficient evidence to demonstrate superiority or noninferiority.

\footnotetext{
From the Department of Surgery, Duke University School of Medicine, Durham, NC. Disclosures: The authors reported no conflicts of interest.

The Journal policy requires editors and reviewers to disclose conflicts of interest and to decline handling or reviewing manuscripts for which they may have a conflict of interest. The editors and reviewers of this article have no conflicts of interest.

Received for publication Nov 16, 2020; revisions received Nov 16, 2020; accepted for publication Nov 17, 2020; available ahead of print Nov 24, 2020.

Address for reprints: Edward P. Chen, MD, Department of Surgery, Duke University School of Medicine, DUMC 3442, Durham, NC 27710 (E-mail: Edward.p.chen@ duke.edu).

J Thorac Cardiovasc Surg 2022;164:1439-40

$0022-5223 / \$ 36.00$

Copyright (c) 2020 by The American Association for Thoracic Surgery

https://doi.org/10.1016/j.jtcvs.2020.11.068
}

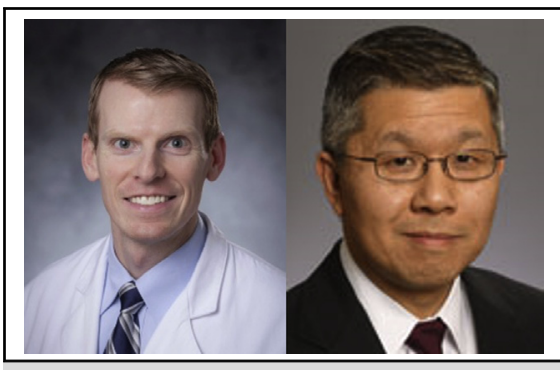

Adam R. Williams, MD, and Edward P. Chen, MD

CENTRAL MESSAGE

Cannulation of the innominate

artery is safe and can be used as

an alternative to the axillary ar-

tery for ACP during proximal

arch surgery.

The majority of these studies have relied on clinical neurologic end points rather than neurocognitive testing or radiographic imaging analysis. In a novel, prospective randomized trial comparing deep HCA with RCP to moderate HCA with ACP, despite evidence of clinical stroke in 1 patient in each study group, $100 \%$ of the moderate HCA plus ACP patients had DW-MRI lesions compared with $45 \%$ of deep HCA plus RCP patients. ${ }^{2}$ Thus, the incidence of neurologic injury after aortic arch surgery is poorly understood and may be notably higher than previously reported.

In contemporary aortic arch surgery, the incidence of clinically significant stroke is about $5 \%$ in elective cases and up to $12 \%$ in emergency settings. ${ }^{3}$ New lesions seen on MRI rarely lead to clinically significant neurological deficits and require more rigorous and long-term cognitive assessments to better understand their influence on brain function. Indeed, these silent infarcts have been shown to lead to subtle cognitive dysfunction and increased risk of cognitive decline. ${ }^{4}$

One concern regarding the study design lies in the use of separate central aortic cannulation along with innominate cannulation in those patients having ACP via the innominate artery. The justification for a second cannulation site was not entirely clear because this represents a difference in the surgical conduct when compared with patients having $\mathrm{ACP}$ via the axillary artery. Another potential area of weakness was the lack of adjudicating neurologic injury by a neurologist postoperatively. 
We congratulate the authors on this study and using DWMRI to more thoroughly assess neurologic injury following aortic arch surgery.

\section{References}

1. Peterson MD, Garg V, Mazer CD, Chu MW, Bozinovski J, Dagenais F, et al. A randomized trial comparing axillary versus innominate artery cannulation for aortic arch surgery. J Thorac Cardiovasc Surg. 2022;164:1426-38.e2.
2. Leshnower BG, Rangaraju S, Allen JW, Stringer AY, Gleason TG, Chen EP. Deep hypothermia with retrograde cerebral perfusion versus moderate hypothermia with antegrade cerebral perfusion for arch surgery. Ann Thorac Surg. 2019;107: 1104-10.

3. Thomas M, Li Z, Cook DJ, Greason KL, Sundt TM. Contemporary results of open aortic arch surgery. J Thorac Cardiovasc Surg. 2012;144: 838-44.

4. Vermeer SE, Longstreth WT, Koudstaal. Silent brain infarcts: a systematic review. Lancet Neurol. 2007:6:611-9.
See Article page 1426.

\section{Commentary: Axillary versus innominate artery cannulation for proximal aortic arch surgery}

\author{
John S. Ikonomidis, MD, PhD
}

The efficacy of cerebral protection measures during operations on the aortic arch likely remains the most important determinant of favorable postoperative neurologic outcomes. Deep hypothermia with complete circulatory arrest was the gold standard for years, but surgeons were always concerned about the actual "safe" duration of cold ischemia on the brain, the deleterious systemic effects of profound hypothermia, and the untoward sequelae of the prolonged cardiopulmonary bypass (CPB) times required to cool and then rewarm. In response to this, surgeons began to experiment with warmer circulatory arrest temperatures, requiring shorter cooling and rewarming times, supplemented with either retrograde or antegrade cerebral perfusion.

Antegrade cerebral perfusion was originally delivered directly, simultaneously through the ostia of both the innominate and left common carotid arteries with the arch open during the circulatory arrest period. However,

From the Division of Cardiothoracic Surgery, Department of Surgery, University of North Carolina School of Medicine, Chapel Hill, NC.

Supported by National Heart, Lung, and Blood Institute Grants 2R01 HL102121 and 1R21 HL148363.

Disclosures: The author reported no conflicts of interest.

The Journal policy requires editors and reviewers to disclose conflicts of interest and to decline handling or reviewing manuscripts for which they may have a conflict of interest. The editors and reviewers of this article have no conflicts of interest.

Received for publication Nov 11, 2020; revisions received Nov 11, 2020; accepted for publication Nov 13, 2020; available ahead of print Nov 25, 2020.

Address for reprints: John S. Ikonomidis, MD, PhD, Division of Cardiothoracic Surgery, Department of Surgery, UNC School of Medicine, 3034 Burnett Womack Building, 160 Dental Circle, Chapel Hill, NC 27599-7065 (E-mail: john_ikonomidis@med.unc.edu).

J Thorac Cardiovasc Surg 2022;164:1440-1

$0022-5223 / \$ 36.00$

Copyright (c) 2020 by The American Association for Thoracic Surgery

https://doi.org/10.1016/j.jtcvs.2020.11.050

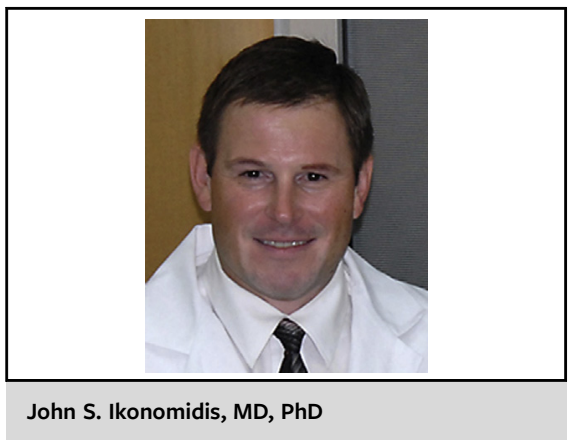

CENTRAL MESSAGE

A unique randomized trial comparing axillary versus innominate artery perfusion for cerebral protection during proximal aortic arch surgery is reviewed.

this strategy can be a bit cumbersome in terms of cluttering the operative field, and also may create confusion in terms of true lumen perfusion in the setting of aortic dissection. Subsequent to this was the introduction of selective antegrade cerebral perfusion (SACP), delivered via perfusion of the right common carotid artery via the right axillary artery. Excellent results have been achieved with this technique, owing to the high percentage of patients with an intact circle of Willis. However, accessing the axillary artery requires an incision distinct from the sternotomy incision, partial division of the pectoralis major and minor muscles, dissection within the brachial plexus, and manipulation of an arterial vessel that probably is secondary only to the pulmonary artery in fragility. From here, direct cannulation of the more stout innominate artery was introduced. This is a more attractive SACP option because this artery can be accessed via a sternotomy incision 